\title{
Artificial neural network models for predicting relationships between diameter at breast height and stump diameter: Crimean pine stands at ÇAKÜ Forest
}

\author{
Modelos de redes neuronales artificiales para predecir las relaciones entre \\ el diámetro a la altura del pecho y el diámetro del tocón: pinos de Crimea en el bosque ÇAKÜ
}

\author{
Muammer Şenyurt a*, İlker Ercanlı a , Alkan Günlü a , Ferhat Bolat a, Sinan Bulut a \\ * Corresponding author: ${ }^{a}$ Çankırı Karatekin University, Faculty of Forestry, Department of Forest Engineering, \\ Çankır1, Turkey, phone+90 3762122757, msenyurt@karatekin.edu.tr, muammer1907@gmail.com, \\ ilkerercanli@karatekin.edu.tr, alkangunlu18@gmail.com, fbolat@karatekin.edu.tr, sbulut@karatekin.edu.tr
}

\begin{abstract}
SUMMARY
This study introduces the artificial neural networks (ANN) function to model relationship between diameter at breast height (dbh) and stump diameter and investigates the potential of ANN model to obtain the prediction of dbh. In total, 583 diameters at breast heightstump diameter pairs were measured in 61 plots sampled from Crimean pine [Pinus nigra subsp. pallasiana] stands in ÇAKÜ Research Forest, Çankırı, Turkey. The network models, including the activation functions of function between input layer and hidden layer and pure-lin function between hidden layer and output layer (A6 alternative) with 12 \# neurons, were found to the better predictive with lower error values including SSE (2585.3869), AIC (821.5731), BIC (825.7817), RMSE (2.2831), MSE (5.2125) and higher fitting value, such as $\mathrm{R}_{\text {adj }}^{2}(0.9372)$, than those of other prediction methods. The best predictive ANN model resulted in the reductions of SSE, AIC, BIC, RMSE and MSE by $9.8486 \%, 5.9018 \%, 5.8735 \%, 5.0519 \%$ and $9.8486 \%$, and $\mathrm{R}_{\text {adj }}^{2}$ in the increase of $0.7377 \%$ as compared to those by the regression model. This present study has underlined the capability of the ANN model for predicting the relationship between dbh and stump diameter. This novel artificial intelligence technique provides a modeling alternative for forest managers to predict dbh required information for the management of forests.
\end{abstract}

Key words: stump diameter, diameter at breast height, Artificial Neural Network, Crimean pine.

\section{RESUMEN}

Este estudio presenta la función de redes neuronales artificiales (ANN) para modelar la relación entre el diámetro a la altura del pecho (dap) y el diámetro del tocón e investigar el potencial del modelo ANN para obtener la predicción de dap. Se midieron 583 diámetros totales en pares de altura del pecho-diámetro de tocón en 61 parcelas muestreadas de pino de Crimea [Pinus nigra subsp. pallasiana] del bosque experimental de ÇAKÜ, Çankırı, Turquía. Se encontró que el modelo de red que incluye las funciones de activación de la función entre la capa de entrada y la capa oculta y la función de -lin entre la capa oculta y la capa de salida (alternativa A6) con 12 neuronas \# fue mejor predictivo, con valores de error más bajos, incluyendo SSE (2585.3869), AIC (821.5731), BIC (825.7817), RMSE (2.2831), MSE (5.2125) y valores de ajuste más altos, como $\mathrm{R}_{\text {adj }}^{2}(0.9372)$, que los de otros métodos de predicción. El mejor modelo predictivo de ANN resultó en la reducción de SSE, AIC, BIC, RMSE y MSE en 9.8486 \%, 5.9018 \%, $5.8735 \%$, 5.0519 \% y $9.8486 \%$, y R ${ }_{\text {adj }}$ con aumento de $0.7377 \%$, en comparación con los modelo de regresión. Este estudio subraya la capacidad del modelo ANN para predecir la relación entre dap y el diámetro del tocón. Esta novedosa técnica de inteligencia artificial proporciona una alternativa de modelado para que los administradores forestales predigan la información requerida sobre dap para el manejo de los bosques.

Palabras clave: diámetro del muñón, diámetro a la altura del pecho, Red Neural Artificial, pino de Crimea.

\section{INTRODUCTION}

The individual diameter at breast height ( $\mathrm{dbh}$ ) is important to forest managers and biometricians for forest inventory, because dbh can be used for obtaining total and merchantable volume, biomass and carbon estimations and developing growth and yield models (Soares and Tomé 2002). The measurements of dbh have lower cost, are less difficult and more precise than other tree attributes, tree height and crown diameter in forest inventory applications (Avery and Burkhart 2001). In some forest operations such as timber cuttings or unrecorded data from harvested stands, dbh of harvested trees cannot be measured at breast height, 1.3 meter. In these circumstances, the stump diameter, measured at $0.3 \mathrm{~m}$, remains as an indicator of the volume of individual harvested trees (Corral-Rivas et al. 2007). 
The stump diameter can be merely measured in these forest areas, and the tree volume and other dendrometric tree attributes can be estimated using the stump diameter measurements (Curtis and Arney 1977). Thus, the relationship between dbh and stump diameter can be assessed as an alternative solution to this difficult situation. It is common practice that dbh is first predicted by using the stump diameter, which is directly measured at some trees, and afterwards the tree volume and other tree attributes can be calculated by using this estimated dbh (Parresol 1998).

As a result of the importance of these relations in the forest inventory, many studies with the graphical analysis date back to the 1940s (Rapraeger 1941). From 1960s, the linear regression analysis, based on the ordinary least squares parameter method, was used to model these relationships between dbh and stump diameter (Myers 1963). These linear regression models require some statistical assumptions: independent, normally distributed and homoscedastic residuals and no multicollinearity among variables or no spatial and longitudinal autocorrelations in data. In the relationship between the stump diameter and dbh, it is possible to achieve a nested stochastic data structure (stand and plot), which can cause a lack of independence among diameter measurements with highly correlated data obtained from different sample plots (West et al. 1984, Gregoire 1987). It is due to this fact that these relationships between the dbh and the stump diameter measured significantly depend on stand structures, where these stand conditions can be differentiated with site quality, stand density and stand ages. The violation of this assumption including a deficiency of independence among diameter measurements resulted in the correlated errors in model estimations, and the biased estimations of the confidence intervals of these model parameters (Searle et al. 1992), and therefore the hypothesis tests and statistical inferences for the developed models, may be invalid (Gregoire 1987).

As an alternative method to solve the autocorrelation problem in these data, Artificial Neural Networks (ANNs), a subset of artificial intelligence, may be a prevailing and operative tool for fitting the relationship between the stump diameter and diameter at breast height without the restrictive assumptions of a particular statistical models. ANNs are a type of artificial intelligence applications inspired from human brain. Thus, ANNs have fitting capability to model compound and nonlinear networks of natural systems without these statistical functions (Atkinson and Tatnall 1997). ANN models have been effectively used in different areas and many circumstances for modeling complex nonlinear relationship. In forestry, some prediction models based on ANNs have been developed to predict tree volume (Özçelik et al. 2010), tree taper (Diamantopoulou 2005b), total tree height (Özçelik et al. 2013), bark volume (Diamantopoulou 2005a), Biomass prediction (Özçelik et al. 2017), basal area and volume increment growth model (Ashraf et al. 2013) and diameter distribution (Diamantopoulou et al. 2015). Besides all these stu- dies predicting various tree and stand attributes, there are no studies using ANN models to predict the relationship between the stump diameter and diameter at breast height and comparing this new prediction method with classical linear and nonlinear regression. Thus, the objective of this study is to develop and evaluate ANN models to predict diameter at breast height from stump diameter for Crimean pine [Pinus nigra Arnold. subsp. pallasiana (Lamb.) Holmboe] stands located in ÇAKÜ Research Forest.

\section{METHODS}

Material. The data for this study were obtained from Çankırı Karatekin University (ÇAKÜ) Forest Faculty Research and Application Forest located at the Çankırı Planning Unit, Çankırı Forest Enterprise, Ankara Regional Directorate of Forestry, Turkey (figure 1). The total area is 367 ha ( 363.5 ha are forest and 3.5 ha are openings in forests). According to the management plan, it consists of Çka-Çkc2-Çkc3-Çkcd1-Çkab3-Çkb3-ÇkÇsbc3-ÇkÇsab3ÇkÇsa-BÇk stands [Çk: Pinus nigra Çs: Pinus sylvestris $\mathrm{L}$, a $(0-7,9 \mathrm{~cm}), \mathrm{b}(8-19,9 \mathrm{~cm}), \mathrm{c}(20-35,9 \mathrm{~cm}), \mathrm{d}(36-51,9 \mathrm{~cm})$ Developmentstages, 1(11-40\%), 2(41-70\%),3(71-100\%): Crown closure, B: Degraded forest, Çkc3: Crimean pine stand, nature development stage $(20-35.9 \mathrm{~cm})$, full coverage. (71-100 \%)].

In these Crimean pine stands, 61 sample plots were subjectively selected to represent various stand conditions such as site quality, age and stand density. The size of circular plots ranged from 0.04 to $0.08 \mathrm{ha}$, depending on stand density to achieve a minimum of 30-40 trees in a sample plot. In each sample plot, individual diameter at breast height $(\mathrm{dbh})$ and stump diameter at $0.3 \mathrm{~m}$ stump height were measured to the nearest $0.1 \mathrm{~cm}$ with calipers for every living tree with $\mathrm{dbh}>4.0 \mathrm{~cm}$. The measurements from living trees without forked and defective broken tops with no obvious evidence of any damages were carried out, and these measurements were included in the statistical analysis in later stages of the study. Thus, $583 \mathrm{dbh}$ stump diameter pairs were used to develop statistical models. These data were randomly split into two data sets, the model fitting and the validation data set. Of those, about 85 $\%$ (497 trees) were used to fit regression model and to train these ANNs models. The remaining 86 trees were reserved for the validations to evaluate these network models. The minimum, maximum, mean and standard deviations for training and validation data were calculated (table 1). Figure 2 presented the relationship between diameter at breast height and stump diameter for training data (A) and validation data $(\mathrm{B})$

Regression analysis models. To determine the relationship between dbh and stump diameters, the following regression equations are fitted by using dbh /stump diameter pairs:

Linear: $\quad d_{1,3=} b_{0}+b_{1} d_{0,3}$ 


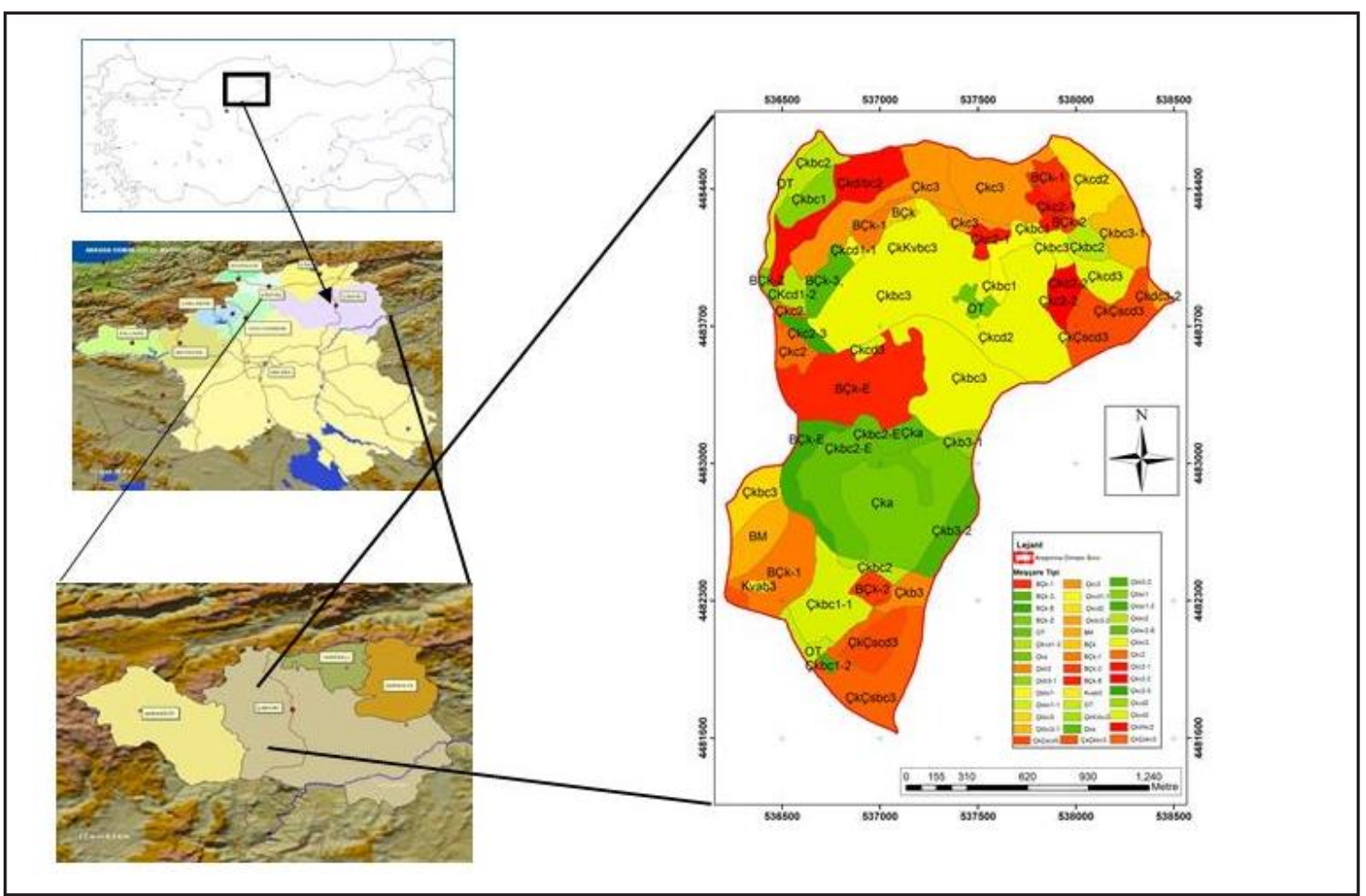

Figure 1. Location of study area.

Ubicación del área de estudio.

Table 1. Summary statistics for sample trees originated from fitting and validation data.

Resumen de estadísticas para los árboles de muestra originadas a partir de datos de ajuste y validación.

\begin{tabular}{llrrrrr}
\hline & Variables & Min. & Max. & Mean & Std. deviation \\
\hline Training data & dbh $(\mathrm{cm})$ & 9.20 & 67.00 & 27.15 & 9.11 \\
& Stump diameter $(\mathrm{cm})$ & 12.30 & 74.00 & 33.33 & 10.10 \\
\hline Validation data & dbh $(\mathrm{cm})$ & 9.40 & 53.50 & 29.75 & 11.41 \\
& Stump diameter $(\mathrm{cm})$ & 13.00 & 64.00 & 36.15 & 12.78 \\
\hline
\end{tabular}

Quadratic: $\quad d_{1,3=} b_{0}+b_{1} d_{0,3}+b_{2} d_{0,3}^{2}$

Logarithmic: $\quad d_{1,3=} b_{0}+b_{1} \ln d_{0,3}$

Power: $\quad d_{1,3}=b_{0} \cdot b_{1}{ }^{d}$

S:

$d_{1,3}=e^{\left(b_{0}+\frac{b_{1}}{d}\right)}$

Compound: $\quad d_{1,3}=b_{0} \cdot b_{1}{ }^{d_{0,3}}$

Inverse:

$$
d_{1,3}=b_{0} \cdot\left(\frac{b_{1}}{d_{0,3}}\right)
$$

Exponential: $\quad d_{1,3}=b_{0} \cdot e^{b_{1} \cdot d_{0,3}}$
[2] Growth: $\quad d_{1,3}=e^{\left(b_{0}+b_{1} d_{0,3}\right)}$

Where, $\mathrm{d}_{1.3}$ : diameter at breast height, $\mathrm{d}_{0.3}:$ stump diameter, [4] $b_{0}, b_{1}$ and $b_{2}$ are the regression model parameters. Curve Estimation Regression Procedure, available in SPSS ver[5] sion 12.0 (SPSS Institute Inc. 2010), was used to model the relationship between the stump diameter and the dia[6] meter at breast height and obtain the parameter predictions of these functions. The estimate of each parameter for variables of these regression models should be statistically significant at $95 \%$ probability level. 

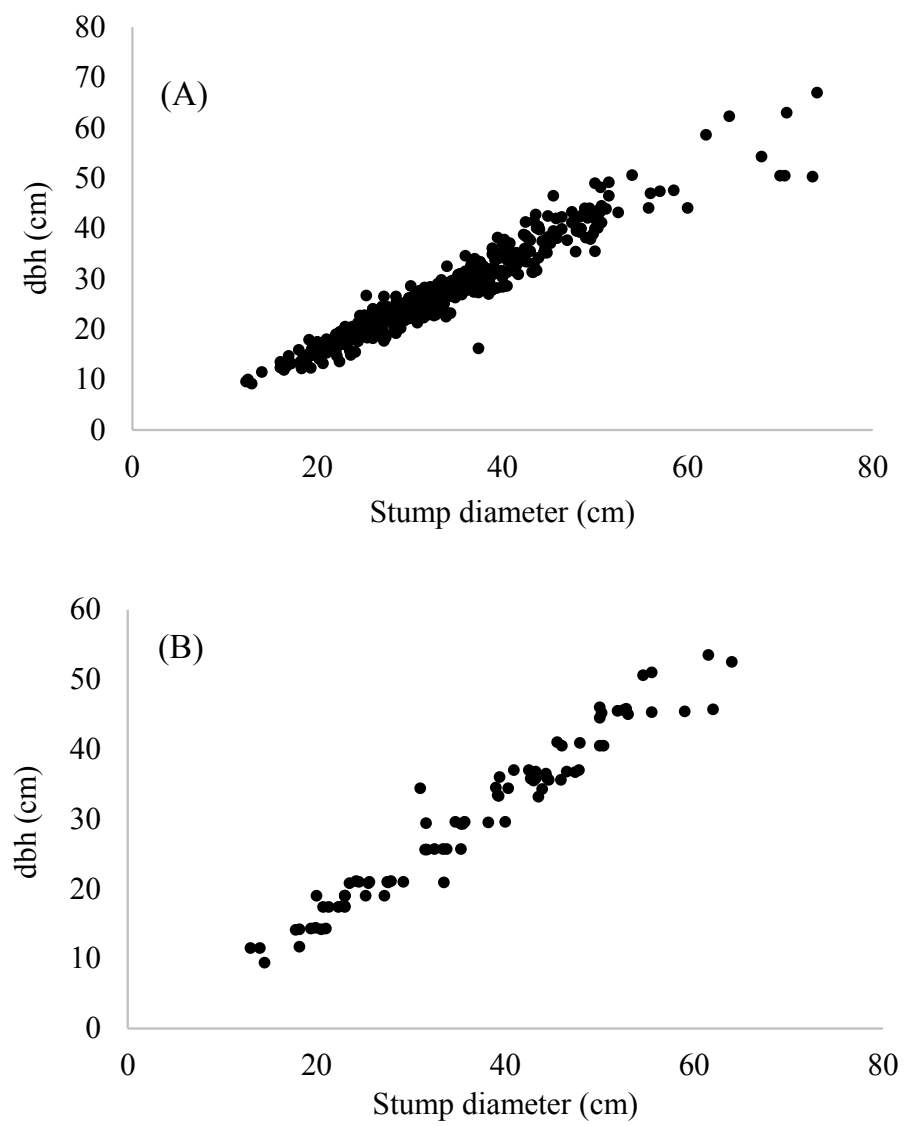

Figure 2. Relationship between diameter at breast height and stump diameter for training data (A) and validation data (B).

Relación entre el diámetro a la altura del pecho y el diámetro del tocón para los datos de entrenamiento (A) y de validación (B).

Artificial neural network models. As another alternative prediction technique, Artificial Neural Network (ANN), based on the feed forward backprop training algorithm with training function of Levenberg-Marquardt, was used to model the relationship between the stump diameter and the diameter at breast height. In ANN training process, the input variable was the tree stump diameters and the target variable was the tree diameter at breast height, which were measured at sample trees. This network structure can include three layers such as input layer, hidden layer and output layer. Correspondingly, some activation functions with hyperbolic tangent sigmoid (tan-sig), logistic sigmoid function (log-sig) and linear function (Pure-lin) connect the network layers. These network structure parameters have significant effects on fitting performance of neural network. In this study, alternatives including some activation functions in the connection between input, hidden and output layers were compared to decide the best predictive one: (A1) tan-sig function between input layer and hidden layer and tan-sig function between hidden layer and output layer, (A2) tan-sig function between input layer and hidden layer and log-sig function between hidden layer and output layer, (A3) tan-sig function between input la- yer and hidden layer and pure-lin function between hidden layer and output layer, (A4) log-sig function between input layer and hidden layer and log-sig function between hidden layer and output layer, (A5) log-sig function between input layer and hidden layer and tan-sig function between hidden layer and output layer, (A6) log-sig function between input layer and hidden layer and pure-lin function between hidden layer and output layer, (A7) pure-lin function between input layer and hidden layer and purelin function between hidden layer and output layer, (A8) pure-lin function between input layer and hidden layer and log-sig function between hidden layer and output layer and (A9) pure-lin function between input layer and hidden layer and tan-sig function between hidden layer and output layer. In some preliminary analyses for these alternatives, A2, A4 and A8 including log-sig function between hidden layer and output layer resulted in non-convergence of ANN models, thus these three alternatives were excluded from the comparisons and evaluations in this study. Another important parameter of the network structure is the number of neurons in hidden layers. Thus, some alternatives for the number of neurons which ranged from 1 to $20 ; 1,2,3, \ldots \ldots 16,17,18,19$ and 20 neuron number 
were compared to determine the best predictive one in this study. As a result, a total of 120 network alternatives including 20 neuron number and 6 transfer function alternatives ( 20 X $6=120$ alternatives) based on the feed forward backprop training algorithm were trained and used to obtain the stump diameter predictions. All these alternatives for training ANN models were carried out using MATLABnntool module (MATLAB 2014).

Comparisons of prediction models. These prediction models including the regression models and ANN models were compared based on goodness-of-fit statistics of Sum of Squared Errors (SSE), Akaike's Information Criterion (AIC), Bayesian Information Criterion (BIC), Root Mean Square Error (RMSE), Mean Squared Error (MSE) and Adjusted Coefficient of Determination $\left(\mathrm{R}^{2}{ }_{\text {adi }}\right)$. Values of SSE, MSE, RMSE, AIC and BIC are desired to be close to 0 , while the $\mathrm{R}_{\text {adj }}^{2}$ close to 1 . The formulas for these statistical values are provided below:

$$
\begin{gathered}
\text { MSE }=\sum_{i=1}^{n} \frac{\left(d_{i}-\widehat{d}_{1}\right)^{2}}{n-p} \\
\text { RMSE }=\sqrt{\sum_{i=1}^{n} \frac{\left(d_{i}-\widehat{d_{1}}\right)^{2}}{n-p}} \\
\text { SSE }=\sum_{i=1}^{n}\left(d_{i}-\widehat{d_{1}}\right)^{2} \\
R_{\text {adj }}^{2}=1-\frac{\sum_{i=1}^{n}\left(d_{i}-\widehat{d_{1}}\right)^{2}(n-1)}{\sum_{i=1}^{n}\left(d_{i}-\bar{d}_{i}\right)^{2}(n-p)} \\
A I C=-2 \log (L)+2 p \\
B I C=-2 \log (L)+p \operatorname{pog}(n)
\end{gathered}
$$

In the formulae listed above: $\mathrm{d}_{i}=$ calculated $\mathrm{dbh} ; \widehat{\mathrm{d}_{1}}=$ estimated dbh; $\bar{d}_{i}=$ mean dbh; $n=$ number of data; $L=$ maximum value of the $\log$ likelihood function; $p=$ number of parameters within the model.

\section{RESULTS}

The values of goodness-of-fit statistics with SSE, AIC, BIC, RMSE, MSE and $\mathrm{R}_{\text {adj }}^{2}$ for the best predictive six Artificial Neural Network models selected from various number of neurons and nine regression equations were given in table 2. For the prediction methods, SSE varied from 2585.3869 to 9415.1578 , AIC from 821.5731 to 1463.9186 , BIC from 825.7817 to 1468.1272 , RMSE from 2.2831 to 4.3569, MSE from 5.2125 to $18.9822, \mathrm{R}_{\text {adj }}^{2}$ from 0.7712 to 0.9372 . Comparing these goodness-of-fit statistics for all prediction methods, the network model --including the activation functions of log-sig function between input layer and hidden layer and pure-lin function between hidden layer and output layer (A6 alternative) with 12 \# neurons-- was found to be the best predictive model with lower error values including SSE (2585.3869), AIC (821.5731), BIC (825.7817), RMSE (2.2831), MSE (5.2125) and higher fitting value such as $\mathrm{R}_{\text {adj }}^{2}(0.9372)$ than those of other prediction methods. Based on these fit statistics, the ANN models commonly presented better statistics including the lower error statistics (SSE, AIC, BIC, RMSE and MSE) with higher $\mathrm{R}_{\text {adj }}^{2}$ than those by these regression models (table 2).

In tables 3 and 4, mean values of these goodness-offit statistics for alternatives including different activation functions and the numbers of neurons were presented to evaluate the effect of the type of activation functions and the number of neurons on stump diameter prediction errors from 120 various alternatives. On the basis of these goodness-of-fit statistics, the activation function alternative including pure-lin function between input layer and hidden layer and pure-lin function between hidden layer and output layer, assigned as A7 alternative, has better mean predictive ability with SSE (2888.7948), $\mathrm{R}_{\text {adj }}^{2}(0.9298)$, MSE (5.8242), RMSE (2.4133), AIC (876.7145), BIC (880.9231) than with the other ANN alternatives based on different activation functions. For the alternatives including the number of neurons, better error and fitting statistics were obtained by 12 neurons with SSE (2804.5983), $\mathrm{R}_{\text {adj }}^{2}$ (0.9318), MSE (5.6544), RMSE (2.3770), AIC (861.2462), BIC (865.4548) than with the other ANN models based on the numbers of neurons.

Figure 3 including the RMSE values visually explicated these evaluations based on the comparisons of various network model alternatives including different activation functions of the numbers of neuron in network architecture. As seen in figure 3, the activation function alternatives including A7 (pure-lin and pure-lin) and A9 (pure-lin and tan-sig) presented monotonous trend according to the change of number of neurons from 1 to 20 , however other activation function alternatives including A1, A3, A5 and A6 showed unstable and inconsistent change in accordance with the number of neurons.

Figure 4 presented the plot of residuals against 1-lagged residuals by the quadratic nonlinear regression model (A) and the best predictive network model including the activation functions of log-sig function between input layer and hidden layer and pure-lin function between hidden layer and output layer (A6 alternative) with 12 \# neurons (B). This plot verified the improvement on the autocorrelation problem by this best predictive ANN model; thus, the ANN model gave no trends in this lag-1 residuals as a function of diameter-lag-1 residuals and this visual finding emphasized the no-autocorrelation problems for the height predictions by this network model (4B). 
In addition to evaluations including fitting abilities of the best predictive ANN model, this ANN model was further evaluated based on the equivalence test procedure (Robinson and Froese 2004, Robinson et al. 2005) including validation dataset, 86 trees. This dataset, as independent data, was not used in training this ANN model. The results of the equivalence test including predicted bootstrap $\mathrm{b}_{0}$ and $\mathrm{b}_{1}$ limits for simulation data are presented in table 5 .
In these ANN models, the null hypotheses of dissimilarity for intercept $\left(b_{0}\right)$ and slope $\left(b_{1}\right)$ parameters were rejected by equivalence tests. The bootstrap intercept $\left(\mathrm{b}_{0}\right) \mathrm{b}_{0}$ and slope $\left(b_{1}\right)$ parameters were contained within the equivalent regions, $\mathrm{y} \pm 10 \%$ and $1 \pm 10 \%$. Thus, the equivalence tests validated the best ANN models including the alternatives for the activation functions and numbers of neurons to the simulation data set.

Table 2. Fit statistics including SSE, AIC, BIC, RMSE, MSE and $\mathrm{R}_{\text {adj }}^{2}$ for the best predictive ANNs models of the number of neuron alternatives regarding the numbers of transfer functions and regression models.

Ajuste de las estadísticas que incluyen: SSE, AIC, BIC, RMSE, MSE y $\mathrm{R}_{\text {adj }}^{2}$ para los mejores modelos predictivos de ANN del número de alternativas neuronales con respecto al número de funciones de transferencia y modelos de regresión.

\begin{tabular}{cccccccc}
\hline $\begin{array}{c}\text { Alternatives for the } \\
\begin{array}{c}\text { activation function and } \\
\text { regression equations }\end{array}\end{array}$ & $\begin{array}{c}\text { Alternatives for } \\
\text { the number of } \\
\text { neuron }\end{array}$ & SSE & AIC & BIC & RMSE & MSE & $R_{\text {adj }}^{2}$ \\
\hline A1 & 17 & 2616.5215 & 827.5225 & 831.7311 & 2.2968 & 5.2752 & 0.9364 \\
A3 & 8 & 2606.3625 & 825.5890 & 829.7976 & 2.2923 & 5.2548 & 0.9367 \\
A5 & 11 & 2602.0358 & 824.7633 & 828.9719 & 2.2904 & 5.2460 & 0.9368 \\
A6 & 12 & 2585.3869 & 821.5731 & 825.7817 & 2.2831 & 5.2125 & 0.9372 \\
A7 & 5 & 2878.8979 & 875.0167 & 879.2253 & 2.4092 & 5.8042 & 0.9300 \\
A9 & 10 & 3089.5997 & 910.1218 & 914.3304 & 2.4958 & 6.2290 & 0.9249 \\
Linear & & 2878.6920 & 874.9811 & 879.1897 & 2.4091 & 5.8038 & 0.9300 \\
Quadratic & & 2867.8271 & 873.1018 & 877.3104 & 2.4046 & 5.7819 & 0.9303 \\
Logarithmic & & 4523.2163 & 1099.5691 & 1103.7777 & 3.0198 & 9.1194 & 0.8901 \\
Power & & 2904.3364 & 879.3890 & 883.5976 & 2.4198 & 5.8555 & 0.9294 \\
S & & 5235.4443 & 1172.2446 & 1176.4532 & 3.2489 & 10.5553 & 0.8728 \\
Compound & & 7982.2711 & 1381.8649 & 1386.0735 & 4.0116 & 16.0933 & 0.8060 \\
Inverse & & 9415.1578 & 1463.9186 & 1468.1272 & 4.3569 & 18.9822 & 0.7712 \\
Exponential & & 7982.2711 & 1381.8649 & 1386.0735 & 4.0116 & 16.0933 & 0.8060 \\
Growth & & 7982.2711 & 1381.8649 & 1386.0735 & 4.0116 & 16.0933 & 0.8060 \\
\hline
\end{tabular}

Table 3. Average values of the fit statistics, including SSE, AIC, BIC, RMSE, MSE and $\mathrm{R}_{\text {adj }}^{2}$, for transfer function alternatives.

Valores medios de las estadísticas de ajuste, incluidos SSE, AIC, BIC, RMSE, MSE y $\mathrm{R}_{\text {adje }}^{2}$ para las alternativas de las funciones de transferencia.

\begin{tabular}{ccccccc}
\hline $\begin{array}{c}\text { Alternatives of the } \\
\text { activation functions }\end{array}$ & SSE & AIC & BIC & RMSE & MSE & $\mathrm{R}^{2}{ }_{\text {adj }}$ \\
\hline A1 & 2894.7243 & 875.8878 & 880.0964 & 2.4135 & 5.8361 & 0.9297 \\
A3 & 3016.9312 & 896.3101 & 900.5187 & 2.4638 & 6.0825 & 0.9267 \\
A5 & 3016.7059 & 894.7089 & 898.9175 & 2.4617 & 6.0821 & 0.9267 \\
A6 & 3028.8102 & 896.3041 & 900.5127 & 2.4662 & 6.1065 & 0.9264 \\
A7 & 2888.7948 & 876.7145 & 880.9231 & 2.4133 & 5.8242 & 0.9298 \\
A9 & 3097.0908 & 911.3240 & 915.5326 & 2.4988 & 6.2441 & 0.9247 \\
\hline
\end{tabular}


Table 4. Mean values of fit statistics, including SSE, AIC, BIC, RMSE, MSE and $\mathrm{R}_{\text {adj }}^{2}$, for the alternatives of number of neuron. Valores medios de las estadísticas de ajuste, incluidos SSE, AIC, BIC, RMSE, MSE y $\mathrm{R}^{2}{ }_{\text {adj }}$, para las alternativas de número de neuronas.

\begin{tabular}{ccccccc}
\hline $\begin{array}{c}\text { Alternatives of the } \\
\text { number of neurons }\end{array}$ & SSE & AIC & BIC & RMSE & MSE & $\mathrm{R}_{\text {adj }}^{2}$ \\
\hline 1 & 2900.4352 & 878.4690 & 882.6776 & 2.4179 & 5.8477 & 0.9295 \\
2 & 2902.6738 & 878.4685 & 882.6771 & 2.4183 & 5.8522 & 0.9295 \\
3 & 2971.7293 & 889.7738 & 893.9824 & 2.4465 & 5.9914 & 0.9278 \\
4 & 2885.4616 & 875.7165 & 879.9251 & 2.4114 & 5.8175 & 0.9299 \\
5 & 2885.7076 & 875.8581 & 880.0666 & 2.4116 & 5.8180 & 0.9299 \\
6 & 2903.5711 & 877.3380 & 881.5466 & 2.4171 & 5.8540 & 0.9294 \\
7 & 2987.4870 & 892.0632 & 896.2718 & 2.4525 & 6.0232 & 0.9274 \\
8 & 3018.9227 & 896.4391 & 900.6477 & 2.4644 & 6.0865 & 0.9266 \\
9 & 3030.8153 & 899.2048 & 903.4133 & 2.4702 & 6.1105 & 0.9264 \\
10 & 2839.2825 & 867.1790 & 871.3875 & 2.3914 & 5.7244 & 0.9310 \\
11 & 3029.1835 & 895.8786 & 900.0872 & 2.4657 & 6.1072 & 0.9264 \\
12 & 2804.5983 & 861.2462 & 865.4548 & 2.3770 & 5.6544 & 0.9318 \\
13 & 3072.5311 & 906.1796 & 910.3882 & 2.4874 & 6.1946 & 0.9253 \\
14 & 3199.4652 & 925.1315 & 929.3400 & 2.5368 & 6.4505 & 0.9223 \\
15 & 3283.1450 & 936.4101 & 940.6187 & 2.5676 & 6.6192 & 0.9202 \\
16 & 3119.8375 & 913.8112 & 918.0197 & 2.5065 & 6.2900 & 0.9242 \\
17 & 2881.2027 & 874.2714 & 878.4800 & 2.4088 & 5.8089 & 0.9300 \\
18 & 3014.2092 & 896.2491 & 900.4577 & 2.4632 & 6.0770 & 0.9268 \\
19 & 3158.3249 & 920.5215 & 924.7300 & 2.5227 & 6.3676 & 0.9233 \\
20 & 3130.8565 & 913.2117 & 917.4203 & 2.5080 & 6.3122 & 0.9239 \\
\hline
\end{tabular}

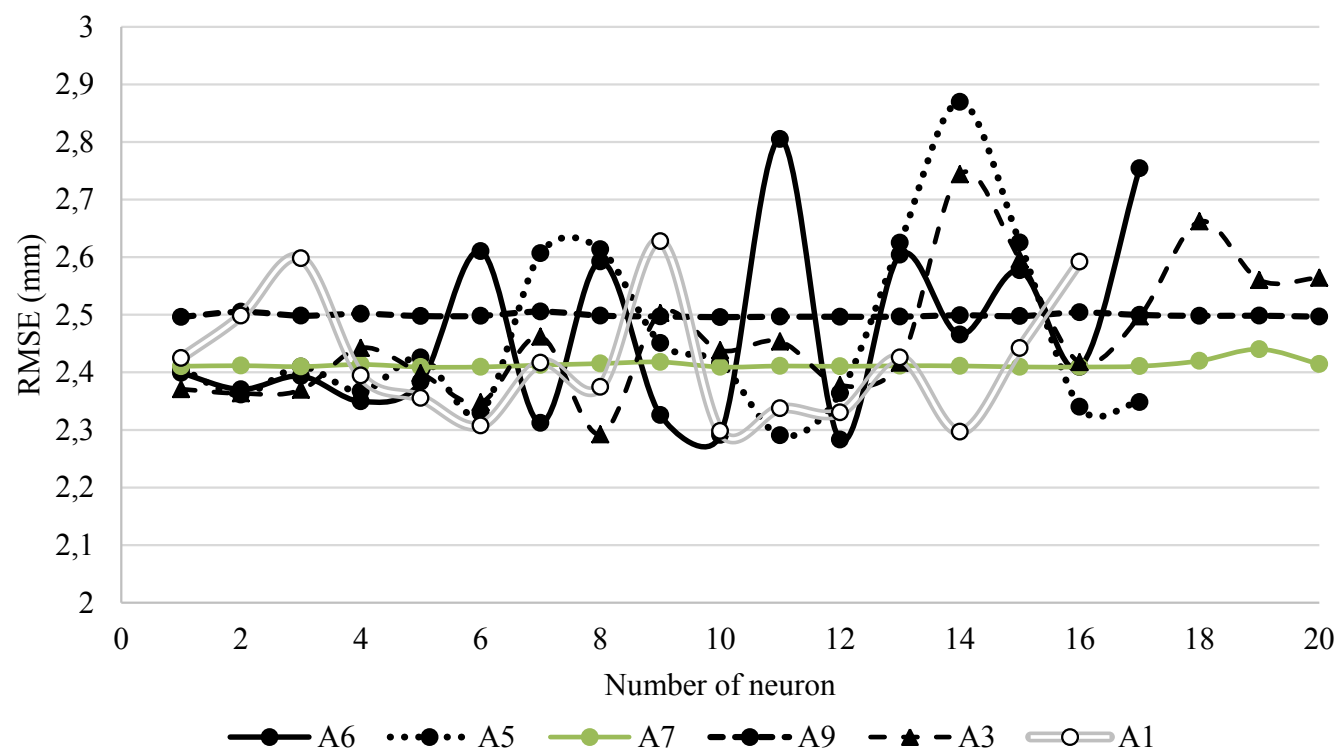

Figure 3. Variation of RMSE of a total of 120 trained ANN models, including transfer functions and number of neurons.

Variación de RMSE de un total de 120 modelos ANN entrenados, que incluyen varias funciones de transferencia y número de neuronas. 


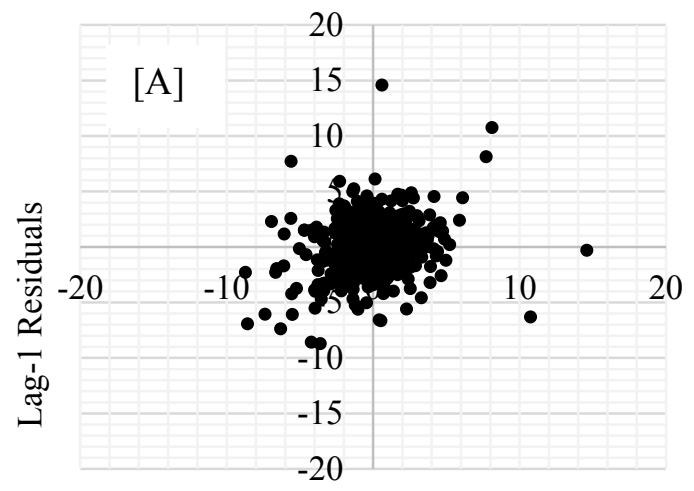

Residuals

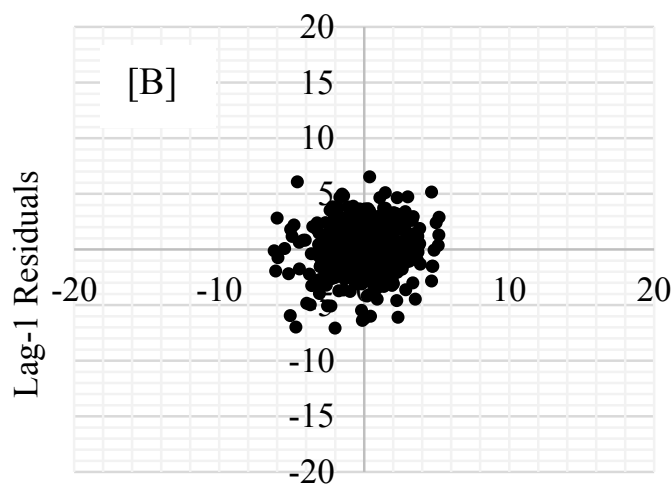

Residuals

Figure 4. The plot of residuals against 1-lagged residuals obtained from the quadratic nonlinear regression (A) and the best predictive network model (B). $\operatorname{red}(\mathrm{B})$.

Gráfica de los residuos frente a los residuos rezagados obtenidos de la regresión no lineal cuadrática (A) y el mejor modelo predictivo de

Table 5. The results of equivalence tests for the ANNs including some alternatives such as the activation functions and the number of neuron.

Resultados de las pruebas de equivalencia para los ANN que incluyen algunas alternativas como las funciones de activación y el número de neuronas.

\begin{tabular}{|c|c|c|c|c|c|c|c|c|c|c|c|}
\hline \multirow{2}{*}{$\begin{array}{l}\text { Alternatives } \\
\text { for the } \\
\text { activation } \\
\text { function }\end{array}$} & \multirow{2}{*}{$\begin{array}{c}\text { Alternatives } \\
\text { for the } \\
\text { number of } \\
\text { neuron }\end{array}$} & \multicolumn{2}{|c|}{$\mathrm{b}_{0}$ limits } & \multicolumn{3}{|c|}{ Bootstrap $b_{0}$ limits } & \multicolumn{2}{|c|}{$\mathrm{b}_{1}$ limits } & \multicolumn{3}{|c|}{ Bootstrap $b_{1}$ limits } \\
\hline & & Lower & Upper & Lower & Upper & $\begin{array}{c}\mathrm{H}_{0} \text { : not } \\
\text { Equivalent }\end{array}$ & Lower & Upper & Lower & Upper & $\begin{array}{c}\mathrm{H}_{0}: \text { not } \\
\text { Equivalen }\end{array}$ \\
\hline A1 & 3 & 25.2835 & 34.2072 & 29.2248 & 30.2895 & Rejected & 0.8500 & 1.1500 & 0.9062 & 1.0189 & Rejected \\
\hline $\mathrm{A} 3$ & 4 & 25.2835 & 34.2072 & 29.1788 & 30.3246 & Rejected & 0.8500 & 1.1500 & 0.8634 & 1.0070 & Rejected \\
\hline A5 & 5 & 25.2835 & 34.2072 & 29.2060 & 30.3036 & Rejected & 0.8500 & 1.1500 & 0.9106 & 1.0239 & Rejected \\
\hline A6 & 12 & 25.2835 & 34.2072 & 29.1342 & 30.3032 & Rejected & 0.8500 & 1.1500 & 0.8534 & 1.0175 & Rejected \\
\hline A7 & 7 & 25.2835 & 34.2072 & 29.2646 & 30.3136 & Rejected & 0.8500 & 1.1500 & 0.9522 & 1.0559 & Rejected \\
\hline A9 & 8 & 25.2835 & 34.2072 & 29.2117 & 30.3250 & Rejected & 0.8500 & 1.1500 & 0.9322 & 1.0477 & Rejected \\
\hline
\end{tabular}

\section{DISCUSSION}

In this study, artificial neural network (ANN) modelling technique has been applied based on its ability to discover relationships between diameter at breast height and stump diameter from data without the requirement of statistical assumptions including a deficiency of independence among diameter measurements, also called as autocorrelation problem in these data. To choose the best predictive architecture of ANN models, different alternatives for the numbers of neurons from 1 to 20 and six transfer functions, a total of 120 ANNs models, were trained and evaluated by comparing some fit statistics with SSE, AIC, BIC, RMSE, MSE and $\mathrm{R}_{\text {adj }}^{2}$. Based on these all fit statistics, the ANN models gave better predictive results with lower values for SSE, AIC, BIC, RMSE and MSE and higher value for $\mathrm{R}_{\text {adj }}^{2}$ than those given by nonlinear regression techniques. Especially, the best predictive ANN model based on the network architecture with the activation functions of log-sig function between input layer and hidden layer and pure-lin function between hidden layer and output layer (A6 alternative) with 12 \# neurons resulted in the reductions of SSE, AIC, BIC, RMSE and MSE by $9.8486 \%, 5.9018 \%, 5.8735 \%, 5.0519 \%$ and $9.8486 \%$, and $\mathrm{R}_{\text {adj }}^{2}$ in the increase by $0.7377 \%$ as compared to those by the quadratic regression model. Considering these fit statistics by the best predictive ANN model, the improvement in these scores was obtained in limited values ranging from $1 \%$ to $10 \%$. However, the best predictive results for the best predictive ANN model were confir- 
med by the lag-graphics with non-trends in residuals as a function of age-lag residuals, in which indicates better solution to the autocorrelation problem in height predictions than those by nonlinear regression technique. These fitting enhancements with non-autocorrelation problems in dbh predictions offered that the ANNs models should be taken into account and given significance since they are alternatives and novel prediction techniques according to the nonlinear regression techniques. Prominently, these fitting improvements in height predictions suggested that the ANN models can be an alternative to the nonlinear regression techniques, such as NLA and NLME. The results of this study are consistent with those from Hasenauer et al. (2001), Diamantopoulou (2005ab), Özçelik et al. (2010, 2017), Leite et al. (2011), Soares et al. (2011), Ashraf et al. (2013), Diamantopoulou et al. (2015), especially height predictions by Özçelik et al. (2013).

The results of ANN models can be further evaluated to decide optimum network architecture from some alternatives of the numbers of different transfer functions and numbers of neuron alternatives. From different transfer functions and numbers of neuron alternatives, the transfer functions have significant effect at the fit statistics for dbh; however, the important trend according to the numbers of neurons was not obtained in fitting ability. Generally, increase in the numbers of neurons resulted in higher error values and lower $\mathrm{R}_{\text {adj }}^{2}$ and 15 \# neurons gave worst error values for dbh predictions. It may be due to the fact that an increase in the numbers of neurons has negative effect over ability of convergence for the ANN models and it is considered that more simple network models with a small number of neurons can produce better predictive results for $\mathrm{dbh}$. For this relationship between dbh and stump diameter, the log-sig transfer function between input layer and hidden layer and the pure-lin function between hidden layer and output layer (A6 alternative) provide better information for predicting these relations and consequently gave superior predictions for dbh than those of other network structure. For other transfer function alternatives, the network models including various transfer functions should be evaluated by training various tree and forest attributes. It will be an important assessment for choosing the best predictive ANN model from numerous network alternatives.

When literature regarding the modeling of stump diameter-dbh is evaluated, regression models can successfully predict the individual $\mathrm{dbh}$. This study examined whether ANN models, as a new technique, can be considered as an alternative approach to classical regression models to predict dbh. When the results obtained from this study are evaluated, ANN models are relatively more successful than the regression models. While previous studies on ANN models provide results for estimating many single tree and stand characteristics, this study innovatively examined the possibilities of using ANN models for estimating dbh from stump diameter.
This ANN developed in this study is appropriate to forest managers for predicting unmeasured tree diameter at breast height in certain circumstances, e.g. illegal timber activities or unrecorded data from harvested stands, and then the volume or biomass estimation of these cut trees can be carried out by using the predicted dbh for these studied stands. Thus, the volume or biomass for these lost trees can be calculated by using their predicted dbh. These ANN models may be an important tool to calculate lost biomass by illegal forest cutting in forest management planning and forest inventory studies. This present study has emphasized the ability of ANN models for predicting the relationship between dbh and stump diameter. These ANN models may represent an important tool in forest management planning and biomass evaluations of these studied stands located in Turkey.

\section{ACKNOWLEDGMENTS}

This work was supported by the Çankırı Karatekin University Project Department (CAKU-BAP), Project No: OF090316B05.

\section{REFERENCES}

Ashraf M I, Z Zhao, C P-A Bourque, DA MacLean, F-R Meng. 2013. Integrating biophysical controls in forest growth and yield predictions with artificial intelligence technology. Canadian Journal of Forest Research 43(12): 1162-1171. DOI: https://doi.org/10.1139/cjfr-2013-0090

Atkinson PM, AR Tatnall. 1997. Introduction: neural networks in remote sensing. International Journal of Remote Sensing 18(4): 699-709. DOI: https://doi. org/10.1080/014311697218700

Avery T E, H E Burkhart. 2001. Forest measurements. 5th ed. Boston, USA. McGraw Hill. 456 p.

Corral-Rivas JJ, M Barrio-Anta, AA Agirre-Calderón, U Diéguez-Aranda. 2007. Use of stump diameter to estimate diameter at breast height and tree volume for major pine species in El Salto Durango (Mexico). Forestry 80(1):2940. DOI: https://doi.org/10.1093/forestry/cpl048

Curtis RO, JD Arney. 1977. Estimating D.B.H. from stump diameters in second- growth Douglas-fir. Portland, USA. USDA-Forest Service Pacific Northwest Forest and Range Experiment Station. Note PNW-29730-33. 7 p.

Diamantopoulou M J. 2005a. Artificial neural networks as an alternative tool in pine bark volume estimation. Computers and Electronics in Agriculture 48(3): 235-244. DOI: https:// doi.org/10.1016/j.compag.2005.04.002

Diamantopoulou MJ, 2005b. Predicting fir trees stem diameters using artificial neural network models. Southern African Forestry Journal 205(1): 39-44. DOI: https://doi. org/10.2989/10295920509505236

Diamantopoulou MJ, R Özçelik, F Crecente-Campo, Ü Eler. 2015. Estimation of Weibull function parameters for modelling tree diameter distribution using least squares and artificial neural networks methods. Biosystems Engineering 133:33-45. DOI: https://doi.org/10.1016/j.biosystemseng.2015.02.013 
Gregoire TG. 1987. Generalized error structure for forestry yield models. Forest Science 33:423-444. DOI: https://doi. org/10.1093/forestscience/33.2.423

Hasenauer H, D Merkl, M Weingartner. 2001. Estimating tree mortality of Norway spruce stands with neural networks. Advances in Environmental Research 5(4): 405-414. DOI: https://doi.org/10.1016/S1093-0191(01)00092-2

Leite HG, MLM da Silva, DHB Binoti, L Fardin, FH Takizawa. 2011. Estimation of inside-bark diameter and heartwood diameter for Tectona grandis Linn. trees using artificial neural networks. European Journal of Forest Research 130:263269. DOI: https://doi.org/10.1007/s10342-010-0427-7

Matlab and Statistics Toolbox Release. 2014. The MathWorks, Inc. Natick, Massachusetts, United States.

Myers CA. 1963. Estimating volumes and diameters at breast height from stump diameters, Southwestern Ponderosa pine. USDA Forest Service Research Note RM-9 Rocky Mountain Forest and Range Experiment Station. 2 p.

Özçelik R, MJ Diamantopoulou, JR Brooks, HVWiant. 2010. Estimating tree bole volume using artificial neural network models for four species in Turkey. Journal of Environmental Management 91(3): 742-753. DOI: https://doi. org/10.1016/j.jenvman.2009.10.002

Özçelik R, MJ Diamantopoulou, F Crecente-Campo, U Eler. 2013. Estimating Crimean juniper tree height using nonlinear regression and artificial neural network models. Forest Ecology and Management 306: 52-60. DOI: https://doi. org/10.1016/j.foreco.2013.06.009

Özçelik R, MJ Diamantopoulou, M Eker, N Gürlevık. 2017. Artificial Neural Network Models: An Alternative Approach for Reliable Aboveground Pine Tree Biomass Prediction. Forest Science 63(3): 291-302. DOI: https://doi.org/10.5849/
FS-16-006

Parresol BR. 1998. Prediction and error of baldcypress stem volume from stump diameter. Southern Journal of Applied Forestry 22(2): 69-73. DOI: https://doi.org/10.1093/ sjaf/22.2.69

Rapraeger EF. 1941. Determining tree dbh from stump measurements. USDA Forest Service Northern Rocky Forest and Range Experiment Station, Research Note No. 18. 8 p.

Robinson AP, RE Froese. 2004. Model validation using equivalence tests. Ecological Modelling 176(3-4): 349-358. DOI: https://doi.org/10.1016/j.ecolmodel.2004.01.013

Robinson AP, RA Duursma, JDA Marshall. 2005. A Regressionbased equivalence test for model validation: shifting the burden of proof. Tree Physiology 25: 903-913. DOI: $\underline{\text { https:// }}$ doi.org/10.1093/treephys/25.7.903

Searle SR, G Casella, CE Mc Culloch. 1992. Variance components. USA. John Wiley. 1992.

Soares P, MA Tome. 2002. A tree crown ratio prediction equation for eucalypt plantations. Annals of Forest Science 58(2): 193-202. DOI: https://doi.org/10.1051/forest:2001118

Soares FAA, EL Flôres, CD Cabacinha, GA Carrijo, ACP Veiga. 2011. Recursive diameter prediction and volume calculation of eucalyptus trees using Multilayer Perceptron Networks. Computers and Electronics in Agriculture 78(1): 19-27. DOI: https://doi.org/10.1016/j.compag.2011.05.008

SPSS Institute Inc. 2010. SPSS Base 12.0 user's guide. Chicago, USA.SPSS.

West PW, DA Ratkowsky, AW Davis. 1984. Problems of hypothesis testing of regressions with multiple measurements from individual sampling units. Forest Ecology and Management 7(3): 207-224. DOI: https://doi.org/10.1016/03781127(84)90068-9 